\title{
Engineering anti-Lewis-Y hu3S193 antibodies with improved therapeutic ratio for radioimmunotherapy of epithelial cancers
}

\author{
Ingrid J. G. Burvenich ${ }^{1,2}$, Fook-Thean Lee', Graeme J. O'Keefe ${ }^{2,3}$, Dahna Makris ${ }^{1}$, Diana Cao ${ }^{1}$, Sylvia Gong ${ }^{3}$, \\ Angela Rigopoulos ${ }^{1}$, Laura C. Allan ${ }^{1}$, Martin W. Brechbiel ${ }^{4}$, Zhanqi Liu' ${ }^{1}$, Paul A. Ramsland ${ }^{5,6,7,8}$ \\ and Andrew M. Scott ${ }^{1,2,3,9,10^{*}}$
}

\begin{abstract}
Background: The aim of the study was to explore Fc mutations of a humanised anti-Lewis-Y antibody (IgG1) hu3S193 as a strategy to improve therapeutic ratios for therapeutic payload delivery.

Methods: Four hu3S193 variants (I253A, H310A, H435A and I253A/H310A) were generated via site-directed mutagenesis and radiolabelled with diagnostic isotopes iodine-125 or indium-111. Biodistribution studies in Lewis-Y-positive tumour-bearing mice were used to calculate the dose in tumours and organs for therapeutic isotopes (iodine-131, yttrium-90 and lutetium-177).

Results: ${ }^{111}$ In-labelled I253A and H435A showed similar slow kinetics ( $t_{1 / 2 \beta}, 63.2$ and $62.2 \mathrm{~h}$, respectively) and a maximum tumour uptake of $33.11 \pm 4.05$ and $33.69 \pm 3.77$ percentage injected dose per gramme (\%/D/g), respectively. ${ }^{111}$ In-labelled $1253 \mathrm{~A} / \mathrm{H} 310 \mathrm{~A}$ cleared fastest $\left(t_{1 / 2 \beta}, 9.1 \mathrm{~h}\right)$ with the lowest maximum tumour uptake $(23.72 \pm 0.85 \% \mathrm{ID} / \mathrm{g})$. The highest increase in tumour-to-blood area under the curve (AUC) ratio was observed with the metal-labelled mutants $\left({ }^{90} \mathrm{Y}\right.$ and $\left.{ }^{177} \mathrm{Lu}\right) .{ }^{177} \mathrm{Lu}-\mathrm{CHX}-\mathrm{A}$ " DTPA-hu3S193 1253A/H310A (6:1) showed the highest tumour-to-blood AUC ratio compared to wild type (3:1) and other variants and doubling of calculated dose to tumour based on red marrow dose constraints.

Conclusions: These results suggest that hu3S193 Fc can be engineered with improved therapeutic ratios for ${ }^{90} \mathrm{Y}$ - and ${ }^{177} \mathrm{Lu}$-based therapy, with the best candidate being hu3S193 1253A/H310A for ${ }^{177} \mathrm{Lu}$-based therapy.
\end{abstract}

Keywords: Therapeutic ratio, Payload delivery, Antibody engineering, Small animal imaging, Lewis-Y

\section{Background}

The use of monoclonal antibodies (mAbs) to deliver radioisotopes to tumour sites (radioimmunotherapy (RIT)) has been very successful in the treatment of haematologic tumours as the targeted radiation is able to kill the highly radiosensitive leukemias and lymphomas. Treatment of solid tumours that are generally more radioresistant has been less successful due to several factors

\footnotetext{
* Correspondence: andrew.scott@onjcri.org.au

${ }^{1}$ Tumour Targeting Laboratory, Ludwig Institute for Cancer Research and Olivia Newton-John Cancer Research Institute, Melbourne, VIC, Australia ${ }^{2}$ School of Cancer Medicine, La Trobe University, Melbourne, VIC, Australia Full list of author information is available at the end of the article
}

including long serum persistence, poor tumour penetration and slow diffusion rates of mAbs [1]. The large molecular size of mAbs $(150 \mathrm{kDa})$ does not allow renal excretion. In addition, the Fc fragment of IgG antibodies interacts with the neonatal $F_{c}$ receptor (FcRn, Brambell receptor), preventing it from being degraded in the lysosomes [2-6]. The resulting long serum persistence of large-sized mAbs cause dose-limiting radiotoxicity to normal tissues, principally red marrow.

The choice of the optimal radionuclide for RIT depends on its intended use. Physical properties such as path length, emission energy and physical half-life must correlate with a particular tumour size. ${ }^{131} \mathrm{I}$

\section{Springer}


$\left(E_{\max }, 0.66 \mathrm{MeV}\right)$, suitable for tumours $<1 \mathrm{~cm}$, and ${ }^{90} \mathrm{Y}$ $\left(E_{\max }, 2.3 \mathrm{MeV}\right)$, suitable for tumours $>1 \mathrm{~cm}$, are both $\beta$-particle-emitting isotopes and have been used in $>95 \%$ of clinical RIT trials [1]. Similar to ${ }^{131} \mathrm{I},{ }^{177} \mathrm{Lu}$ $\left(E_{\max }, \quad 0.5 \mathrm{MeV}\right)$ has been identified as having favourable characteristics for treatment of tumours particularly with heterogeneous antigen expression [7]. Whilst ${ }^{90} \mathrm{Y}$ and ${ }^{177} \mathrm{Lu}$ labels are retained intracellularly after endocytosis, the ${ }^{131} \mathrm{I}$ label is rapidly released from the cells $[8,9]$.

Early engineering approaches to reduce the serum half-life of antibodies and improve therapeutic ratios were based on reduction in antibody size by deletion of constant domains $[1,10,11]$. Our laboratory has previously evaluated smaller forms such as diabody, $\mathrm{F}\left(\mathrm{ab} \mathrm{b}^{\prime}\right)_{2}$ and tetrameric scFv constructs without an Fc fragment. These constructs showed a rapid elimination phase compared to wild-type IgG1, more rapid tumour targeting with the maximum tumour uptake observed at an earlier time point but strongly reduced maximal tumour uptake [12-14]. Another approach studied in preclinical studies to improve therapeutic ratio is pretargeted RIT. The multistep targeting approach allows the antibody to clear first before administrating the therapeutic radionuclide, and this approach has shown high increases in therapeutic ratio $[1,15]$.

The FcRn receptor recycles IgG antibodies into the blood circulation. During the last decade, the Fc-FcRn binding site has been well characterised, with I253, $\mathrm{H} 310$ in the $\mathrm{CH} 2$ domain and $\mathrm{H} 435$ in the $\mathrm{CH} 3$ domain identified as the key residues involved in the Fc-FcRn binding [16-19]. The FcRn-mediated IgG recycling can be described as a three-step process: (1) passive pinocytosis of IgG into endothelial cells; (2) in the acidic environment of endosomes $(\mathrm{pH}<6.5)$, histidine residues in the Fc fragment of IgG become protonated and this allows high-affinity binding of IgG to FcRn; and (3) unbound IgG will undergo lysosomal degradation whilst FcRn-bound IgG is released back into the blood circulation [19]. Therefore, more recent engineering approaches to reduce the serum half-life of antibodies or Fc-coupled biological compounds used for payload delivery focus on mutating the specific amino acids in the $\mathrm{CH} 2$ or $\mathrm{CH} 3$ domain of the Fc fragment involved in the binding site of FcRn. Recycling of the variants is reduced, due to their diminished interaction with the FcRn receptor at $\mathrm{pH}<6.5$. Most work has been done with radiolabelled $\mathrm{Fc}$-containing antibody fragments such as scFv-Fc [20-23] and a minibody [22]. Only one intact radiolabelled antibody (chTNT-3) carrying the I253A mutation has been studied in biodistribution studies and imaging studies [24].

We recently produced anti-Lewis-Y $\left(\mathrm{Le}^{\mathrm{y}}\right)$ humanised IgG1 variants carrying specific mutations in the Fc-FcRn binding region and investigated their binding properties to murine $F c R n(m u F c R n)$ and human FcRn (huFcRn) in vitro and in vivo [25]. A good correlation was found with low in vitro binding to FcRn corresponding to fast blood clearance rates. Differences in blood clearance rates were observed between the murine and human FcRn mouse model, showing that one alanine mutation in the Fc-huFcRn binding site (i.e. I253A, H310A or H435A) was sufficient to completely abrogate binding to huFcRn and generate hu3S193 antibodies with clearance rates as fast as hu3S193 antibody fragments (e.g. $\left(\mathrm{Fab}^{\prime}\right)_{2}$ ) without an Fc fragment. In contrast, two alanine mutations in hu3S193 Fc (e.g. I253A/H310A) were necessary to completely abrogate binding to muFcRn. Single nonalanine variants of hu3S193 that were able to completely abrogate muFcRn binding were I253D, I253P, H310D and H310E [25].

This study explored the impact of amino acid substitutions on conserved residues of hu3S193 that have been shown to be critical for maintaining serum persistence of human IgG1 antibodies as a means to improve therapeutic ratios for RIT in solid tumours using intact antibodies. Hu3S193 has been shown to have significant anti-tumour effect in animal models for delivery of radioisotopes, including ${ }^{131} \mathrm{I},{ }^{90} \mathrm{Y}$ and ${ }^{177} \mathrm{Lu}$ [26-29]. A first-in-man phase I trial of hu3S193 in patients with $\mathrm{Le}^{\mathrm{y}}$ expressing tumours clearly showed the potential for delivery of radioisotopes using hu3S193 for selective targeting of solid tumours [31]. The utility of hu3S193 mutants in cancer diagnosis and therapy were evaluated by pharmacokinetic, biodistribution, dosimetry and immunoscintigraphy studies in tumour-bearing mice.

\section{Methods}

\section{Construction of hu3S193 mutant antibodies}

The construction and production of hu3S193 and huA33 has been described before [31, 32]. The hu3S193 heavy chain $(\mathrm{HC})$ was ligated into the pEE6.4 mammalian expression vector (Lonza Biologics, Slough, UK) via a HindIII and EcoRI double digest (pEE6.4/hu3S193 HC). pEE6.4/hu3S193 HC was used as a template for site-directed mutagenesis (GeneTailor ${ }^{\mathrm{ma}}$ Site-Directed Mutagenesis System (Invitrogen) or QuickChange II XL Site-Directed Mutagenesis Kit (Stratagene) to introduce the following substitutions in the $\mathrm{CH} 2$ and $\mathrm{CH} 3$ domains: I253A, H310A, H435A and I253A/H310A [25]. The hu3S193 kappa light chain was ligated into the pEE14.4 mammalian expression vector containing the glutamine synthetase gene (Lonza Biologics) via a HindIII and EcoRI double digest. For the simultaneous expression of each mutated hu3S193 antibody, light and mutated heavy chain genes were cloned into a doublegene vector (pDGV) using a NotI and $P v u \mathrm{I}$ double digest. Freestyle $293-\mathrm{F}$ cells $\left(1 \times 10^{6}\right.$ cells $\left./ \mathrm{mL}\right)$ were 
transfected with the pDGV constructs according to the manufacturer's instructions (Invitrogen). Supernatants were harvested at $96 \mathrm{~h}$ post transfection. Hu3S193 antibodies were purified using HiTrap KappaSelect columns (GE Healthcare). Purified proteins were analysed by SDS-PAGE under non-reducing conditions and evaluated by size exclusion chromatography on a Superdex 200 HR 10/30 column (GE Healthcare) using $0.01 \mathrm{~mol} / \mathrm{L}$ sodium phosphate and $0.15 \mathrm{~mol} / \mathrm{L} \mathrm{NaCl}(\mathrm{pH} 7.2)$ as elution buffer.

\section{In vitro binding to Lewis-Y and protein A of hu3S193 mutant antibodies}

The Lewis-Y binding activity of hu3S193 antibodies was determined by BIAcore analysis using a synthetic Lewis-Y tetrasaccharide coupled to BSA (Alberta Research Council, Edmonton, Alberta, Canada) on a CM5 chip using a BIAcore 2000 as described (BIAcore AB, Uppsala, Sweden) [30]. Hu3S193 antibody samples were diluted in HBS buffer (10 mM HEPES, $\mathrm{pH} 7.4$, $150 \mathrm{mM} \mathrm{NaCl}, 3.4 \mathrm{mM}$ di-Na-EDTA and $0.005 \%$ Tween 20). Aliquots $(60 \mu \mathrm{L})$ were injected over the sensor chip surface at a flow rate of $30 \mu \mathrm{L} / \mathrm{min}$. After the injection phase, dissociation was monitored by flowing HBS over the chip surface for $300 \mathrm{~s}$. Bound antibody was eluted, and the chip surface was regenerated between samples by injection of $100 \mathrm{mM} \mathrm{HCl}$. For kinetic analysis, varying concentrations of hu3S193 wild type and mutants were injected $(10,19,38,75$ and $150 \mathrm{nmol} / \mathrm{L}$ ). Global analysis using a 1:1 Langmuir model fit was performed using BIA-evaluation version 4.1.1 software.

Fluorescence-activated cell sorter (FACS) analysis was done on Lewis-Y-positive A431 skin cancer cells. Aliquots of $2 \times 10^{5}$ cells were incubated with hu3S193 antibodies $(200 \mathrm{nmol} / \mathrm{L})$ in DMEM/F12 medium containing $10 \%$ foetal bovine serum on ice. After washing the cells with PBS, cells were incubated with a goat phycoerythrin-conjugated anti-human IgG (Sigma) and incubated on ice for $30 \mathrm{~min}$. Cells were washed with phosphate-buffered saline and resuspended in a final volume of $300 \mu \mathrm{L}$. In control samples, primary antibody was omitted. Flow cytometric analysis was done using a Guava EasyCyte Plus flow cytometer. Cancer cell populations were gated based on forward and side scatter variables. Data analysis was done using WinMDI (Joseph Trotter).

\section{Radiolabelling of hu3S193 antibodies}

Hu3S193 antibodies were radiolabelled with four isotopes: ${ }^{125} \mathrm{I},{ }^{131} \mathrm{I},{ }^{111} \mathrm{In}$ and ${ }^{177} \mathrm{Lu}$. Iodine-125 and lutetium-177 were obtained from PerkinElmer (PerkinElmer Life and Analytical Sciences, Waltham, MA), iodine-131 was obtained from ANSTO (ANSTO, Menai, Australia) and indium-111 was obtained from MDS Nordion (Canada).

Radioiodination was performed using $\mathrm{pH}$-neutralised isotopes, catalysed by iodogen-coated glass beads as previously published [12, 33]. After a 10-min incubation period, the reaction mixture was purified through a Sephadex G50 desalting column (Sigma-Aldrich, Sydney, Australia) equilibrated with $0.9 \% \mathrm{NaCl}$ containing $0.05 \%$ human serum albumin.

Radiolabelling of the hu3S193 antibody constructs with indium-111 and lutetium-177 was done by using the bifunctional metal ion chelate $\mathrm{C}$-functionalized transcyclohexyl diethylenetriaminepentaacetic acid (CHX-A" DTPA) [34, 35]. A chelate to antibody ratio of 3:1 was employed, using $0.1 \mathrm{M}$ sodium bicarbonate buffer $(\mathrm{pH}$ 8.6) containing $0.9 \% \mathrm{NaCl}$. Incubation was allowed for $16 \mathrm{~h}$ at room temperature. Under these conditions, one to two chelates are expected per antibody molecule. The radiolabelled mixture was purified through a Sephadex G50 desalting column equilibrated with $0.9 \% \mathrm{NaCl}$ containing $0.05 \%$ human serum albumin.

Radiolabelling was performed on the day of injection into mice. Prior to injection, the percentage of unbound radionuclide content was determined by ITLC as previously described [36]. Determination of the immunoreactivity of radiolabelled hu3S193 antibody constructs was performed by a single-point binding assay, where $10 \times$ $10^{6} \mathrm{Le}^{\mathrm{y}}$-positive A431 cells were incubated with $20 \mathrm{ng}$ of radiolabelled antibody constructs for $45 \mathrm{~min}$ at room temperature with continuous mixing throughout to keep the cells in suspension. Cells were washed three times, and pellets were measured in a gamma counter (Cobra II, Model 5002, Packard Instruments, Canberra, Australia). Three samples of radiolabelled antibody at the same concentration as that initially added to the cells were measured at the same time of the cell pellets, and immunoreactivity was calculated: (cpm cell pellet/ mean $\mathrm{cpm}$ radioactive antibody standards $) \times 100$. Serum stability was analysed by determination of immunoreactivity on the day of injection, at $48 \mathrm{~h}$, and 7 days after $20 \mathrm{ng}$ of radiolabelled antibody was incubated in human serum at $37^{\circ} \mathrm{C}$.

\section{Blood clearance studies}

Female athymic mice (BALB/c nu/nu; 4-6 weeks; Animal Resources Centre) were injected in the tail vein with $0.185 \mathrm{MBq}{ }^{125} \mathrm{I}$-mutant $(2.5-5 \mu \mathrm{g}, 5 \mu \mathrm{Ci})$ and $0.185 \mathrm{MBq}{ }^{131} \mathrm{I}$-hu3S193 $(2.5-5 \mu \mathrm{g}, 5 \mu \mathrm{Ci})$ wild type antibody $(n=5)$. A separate group of athymic mice were injected with $0.185 \mathrm{MBq}{ }^{125} \mathrm{I}$ - hu3S193 mutant (2.5$5 \mu \mathrm{g}, 5 \mu \mathrm{Ci})$ and $0.185 \mathrm{MBq}{ }^{111} \mathrm{In}-\mathrm{hu} 3 \mathrm{~S} 193(2.5-5 \mu \mathrm{g}$, $5 \mu \mathrm{Ci})$ mutant $(n=5)$. All animal studies were approved by the Austin Hospital Animal Ethics Committee and were conducted in compliance with NHMRC Australian 
code of practice for the care and use of animals for scientific purposes. Blood samples $(10-20 \mu \mathrm{L})$ were collected from groups of five at $5 \mathrm{~min}, 1,2,4,8,24,48$, $72,120,168,240$ and $336 \mathrm{~h}$ after injection of radioactive antibodies. Samples were counted in a gamma counter (Cobra II). Standards prepared from injected material were counted each time with blood samples enabling calculations to be corrected for physical decay of isotope.

\section{Biodistribution studies}

Biodistribution studies were done with athymic nontumour-bearing mice (BALB/c nu/nu, female, 4-6 weeks) or mice bearing A431 tumours $\left({ }^{111} \mathrm{In}, 0.657 \pm 0.216\right.$ g; $\left.{ }^{131} \mathrm{I}, 0.515 \pm 0.195 \mathrm{~g} ;{ }^{177} \mathrm{Lu}, 0.466 \pm 0.086 \mathrm{~g}\right)$. To study the tumour uptake and biodistribution in normal tissues of radioiodinated hu3S193 variants, A431 tumour-bearing $\mathrm{BALB} / \mathrm{c} n u / n u$ mice were co-injected intravenously with 0.185-0.74 MBq $(5-20 \mu \mathrm{Ci}){ }^{131} \mathrm{I}$-hu3S193 variants $(2-$ $6 \mu$ g protein) and $0.185-0.74 \mathrm{MBq}{ }^{125} \mathrm{I}$-hu3S193 wild type (2-6 $\mu \mathrm{g}$ protein). In a second study, 0.185$0.74 \mathrm{MBq}{ }^{111}$ In-CHX-A" DTPA-labelled mutant (2$6 \mu \mathrm{g}$ protein) and $0.185-0.74 \mathrm{MBq}{ }^{125}$ I-labelled hu3S193 wild type (2-6 $\mu \mathrm{g}$ protein) were co-injected. ${ }^{111} \mathrm{In}-\mathrm{CHX}$ A" DTPA-labelled wild type and ${ }^{125} \mathrm{I}$-hu3S193 wild type were also injected as a control group. ${ }^{125} \mathrm{I}$-hu3S193 wild type was used as an internal control in all injected animals to enable direct comparison between the different mutants. Typically, groups of four to five mice were sacrificed at $4,24,48,72,120,168$, and 240 or $288 \mathrm{~h}$ after injection of radiolabelled antibodies. For evaluation of ${ }^{177} \mathrm{Lu}$-labelled antibodies, mice were sacrificed at $48 \mathrm{~h}$ after injection. At the designated time points, groups of mice $(n=4-5)$ were humanely sacrificed by overinhalation of isoflurane. Mice were bled by cardiac puncture, and tumours and organs (skin, liver, spleen, small intestine, stomach, kidney, brain, bone (femur), lungs and heart) were immediately removed and blotted dry. All samples were weighed and counted in a dual gamma scintillation counter (Cobra II, Packard Instruments). Triplicate standards prepared from the injected material were counted at each time point with tissue and tumour samples enabling calculations to be corrected for the physical decay of the isotopes. Results of the radiolabelled antibody distribution over time were calculated as the mean percentage injected dose per gramme $(\% \mathrm{ID} / \mathrm{g} \pm \mathrm{SD})$ for each mutant and parental hu3S193 per time point.

\section{Pharmacokinetic analysis and predictive dosimetry}

Antibody serum concentrations were expressed as percentage injected dose per millilitre $(\% \mathrm{ID} / \mathrm{mL})$, and the blood concentrations $(\mu \mathrm{g} / \mathrm{mL})$ were calculated. A twocompartment IV bolus model with macro-parameters, no lag time and first order elimination (WinNonlin Model 8) was fitted to serum data obtained from blood clearance studies for each animal using unweighted non-linear, least squares with WinNonLin version 5.2 (Pharsight Corp., Mountain View, CA). Estimates were determined for the pharmacokinetic parameters: alpha half-life $\left(t_{1 / 2 \alpha}\right)$, beta half-life $\left(t_{1 / 2 \beta}\right)$, area under the curve extrapolated to infinity $\left(\mathrm{AUC}_{0-\infty}\right)$ and mean residence time (MRT). Alpha half-lives of mutant hu3S193 were constrained to be smaller or equal to the alpha half-life of hu3S193 wild type. Significant differences in these values were examined by comparing the coefficient of variation $(\mathrm{CV} \%)$ for the estimated parameters.

To estimate radioimmunotherapeutic applications for ${ }^{90} \mathrm{Y}$ - or ${ }^{177} \mathrm{Lu}$-labelled mutants, biodistribution data obtained with ${ }^{111}$ In-CHX-A" DTPA-labelled antibodies were used to generate time-activity curves for the calculations of predictive radiation doses for the bone marrow, liver, kidneys and tumour. Identical biodistribution and biologic clearance of ${ }^{111} \mathrm{In}$-, ${ }^{90} \mathrm{Y}$ - and ${ }^{177} \mathrm{Lu}$-labelled antibodies were assumed. Predictive dosimetric analysis was also done for ${ }^{131}$ I-labelled antibodies based on biodistribution data obtained with ${ }^{125}$ I-labelled antibodies. As radiation absorbed doses are proportional to $\% \mathrm{ID} / \mathrm{g}$, time-activity curves for the blood, liver, kidneys and tumour were integrated over time to calculate area under the curve (AUC). Time-activity curves generated from biodistribution data were corrected for radiodecay. Therefore, the pharmacokinetic values calculated from such data refer to pharmacological values of the antibodies in the absence of radioisotope. Appropriate physical half-life corrections were applied to convert $\% \mathrm{ID}_{\text {pharmacological }} / \mathrm{g}$ to $\% \mathrm{ID}_{\text {radioisotope }} / \mathrm{g}$, and the time-activity curves were fit to either a two or three exponential function from which the AUC is determined for ${ }^{90} \mathrm{Y},{ }^{177} \mathrm{Lu}$ and ${ }^{131} \mathrm{I}$. AUC integration from zero to infinity was done by the sum of a trapezoidal integration of the measurement range $\left(\mathrm{AUC}_{0-288} \mathrm{~h}\right)$ plus an extrapolated model fit for the extrapolated range $\left(\mathrm{AUC}_{288 \mathrm{~h}-\infty}\right)$. To calculate accumulated activity, photon dose and edge effects were ignored. Dose to red marrow was determined from blood concentrations using a baseline value of 0.1 [21].

\section{Nano-SPECT and MR imaging}

All the SPECT and MR scans were performed on a small animal nano-SPECT/CT imaging system and a small animal nano-PET/MR imaging system (Mediso nano-Scan ${ }^{\mathrm{PM}}$, Mediso Medical Imaging Systems, Budapest, Hungary) individually. Groups of two mice were injected with 3.7 MBq $(270 \mu \mathrm{g}){ }^{177} \mathrm{Lu}-\mathrm{CHX}-\mathrm{A}^{\prime \prime}$ DTPA-labelled antibody (huA33 wild type, hu3S193 wild type or hu3S193 I253A/ H310) and serially imaged at 2 days post injection. Imaging procedures involved anaesthesia of mice by isoflurane. Each mouse was scanned in supine position with its head secured via ear and tooth bars. Respiration was 
monitored by a pressure-sensitive pad adhered to the abdomen. The imaging study started with a whole body T1-weighted MR scan, followed by a 60-min SPECT scan which was reconstructed into a volumetric image with the voxel size of $0.3 \mathrm{~mm} \times 0.3 \mathrm{~mm} \times 0.3 \mathrm{~mm}$ using the Mediso Tera-TOMO $^{\circ}$ Monte Carlo-based algorithm. Subsequently, reconstructed SPECT and MR images were transferred to a research PACS system where the images could be retrieved for further processing and analysis.

To confirm data obtained from imaging, groups of five mice bearing A431 tumours were injected with $6.29 \mathrm{MBq}(100 \mu \mathrm{g}){ }^{177} \mathrm{Lu}-\mathrm{CHX}-\mathrm{A}$ " DTPA-labelled antibody (huA33 wild type, hu3S193 wild type or hu3S193 I253A/H310) and sacrificed at $48 \mathrm{~h}$ post injection. Organs and blood were collected as described before, and the radiolabelled antibody distribution over time was calculated as the mean $\% \mathrm{ID} / \mathrm{g} \pm \mathrm{SD}$ for each antibody per time point.

\section{Statistical analysis}

To compare tumour uptake at different time points for the mutants versus hu3S193 wild type, two-way ANOVA with the Bonferroni post test was performed using GraphPad Prism version 5.00 for Windows, GraphPad Software, San Diego California USA www.graphpad.com. Tumour-to-tissue ratios or tissue uptake at specific time points were analysed using one-way ANOVA with Tukey's multiple comparison post test. When less than three groups were compared, a non-parametric $t$ test (one-tailed) was used.

\section{Results}

\section{Production of hu3S193 variants with short elimination} half-lives

To investigate whether hu3S193 antibodies with reduced serum persistence would benefit payload delivery, three hu3S193 single variants (I253A, H310A, H435A) and one double variant (I253A/H310A) were generated. All antibodies were expressed in transiently transfected freestyle 293-F cells. Expression yields of antibodies ranged from 15 to $40 \mathrm{mg} / \mathrm{L}$ in shake flasks containing $60 \mathrm{~mL}$ medium. HiTrap KappaSelect columns were used to purify antibodies. Quality control using SDS-PAGE and HPLC on a Superdex 200 column showed highly pure antibody preparations with $>98 \%$ purity. All mutants maintained effective antigen binding in FACS analysis and BIAcore (Additional file 1: Table S1).

\section{Radiolabelling of hu3S193 constructs and huA33 control}

Antibodies were radiolabelled with iodine-125 and indium-111, and radiochemical purity of all injected antibodies was more than $98 \%$. Immunoreactivity was determined in the presence of human serum at $37^{\circ} \mathrm{C}$ for up to 6 days of incubation, as measured by percentage of antibody binding to Lewis-Y-positive A431 cells in a single-point immunoreactivity assay. Data presented in Table 1 demonstrates minimal loss in binding of all variants compared to wild type at day 0 due to labelling (20-35\%). Loss of immunoreactivity due to incubation in human serum at $37{ }^{\circ} \mathrm{C}$ was similar for variants and wild type (day 7: 55-70\%).

Blood clearance studies were performed in BALB/c $n u / n u$ mice $(n=5)$ using ${ }^{125}$ I-labelled antibody coinjected with their ${ }^{111}$ In-CHX-A" DTPA-labelled counterpart, and blood clearance parameters were calculated (Table 2). There was no significant difference between the elimination half-lives $\left(t_{1 / 2 \beta}\right)$ of radioiodinated or radiometal-chelated hu3S193 wild type. Radioiodinated hu3S193 variants showed shorter half-lives than their radiometal counterpart; the shorter the half-life the smaller the differences in half-lives observed between radioiodinated and radiometal-chelated hu3S193 mutants. Although different terminal serum half-lives were seen dependent on the choice of isotope, a similar ranking order of area under the curve (AUC) was observed: wild type $>\mathrm{H} 435 \mathrm{~A}=\mathrm{I} 253 \mathrm{~A}>\mathrm{H} 310 \mathrm{~A}>\mathrm{I} 253 \mathrm{~A} /$ H310A (Table 2).

Biodistribution studies in tumour-bearing mice with ${ }^{131} \mathrm{I}-$ and ${ }^{111}$ In-CHX-A" DTPA-labelled hu3S193 antibodies

In general, a significant reduction in tumour uptake was observed with faster clearing variants; the faster the blood clearance of the variant, the higher the reduction in tumour uptake (Fig. 1). Additional file 1: Table S2 shows the biodistribution results of ${ }^{111}$ In-CHX-A" DTPAlabelled antibodies. Additional file 1: Table S3 shows the biodistribution results of ${ }^{131}$ I-labelled antibodies. Twoway ANOVA of differences in tumour uptake at different time points post injection of each variant compared to

Table 1 Immunoreactive fraction (\% total binding) of hu3S193 antibodies incubated in human serum at $37{ }^{\circ} \mathrm{C}$ for 6 days

\begin{tabular}{lllll}
\hline Radiolabel & Antibody & D0 & D2 & D6 \\
\hline${ }^{125}$ I- & Wild type & $78.64 \pm 1.59^{\mathrm{a}}$ & $59.09 \pm 5.54$ & $32.36 \pm 0.12$ \\
& I253A & $66.76 \pm 0.33$ & $47.50 \pm 2.69$ & $30.99 \pm 0.77$ \\
& H310A & $70.75 \pm 3.99$ & $53.52 \pm 3.53$ & $32.95 \pm 0.28$ \\
& H435A & $69.50 \pm 0.33$ & $54.59 \pm 4.68$ & $34.82 \pm 2.98$ \\
& I253A/H310A & $71.93 \pm 3.22$ & $58.29 \pm 0.33$ & $30.52 \pm 1.45$ \\
& Wild type & $86.84 \pm 0.74$ & $64.46 \pm 8.04$ & $40.21 \pm 0.62$ \\
${ }^{111}$ In- & I253A & $83.47 \pm 4.26$ & $59.16 \pm 3.05$ & $40.77 \pm 0.53$ \\
& H310A & $81.03 \pm 3.38$ & $55.83 \pm 1.78$ & $35.64 \pm 0.29$ \\
& H435A & $83.38 \pm 3.81$ & $59.70 \pm 7.27$ & $46.19 \pm 4.63$ \\
I253A/H310A & $86.07 \pm 2.74$ & $57.18 \pm 11.61$ & $42.54 \pm 1.15$ \\
\hline
\end{tabular}

Data are presented as average \pm SD (D2 ${ }^{125} \mid-, n=2 ;$ D6 ${ }^{125} \mid-$ and ${ }^{111} \mid \mathrm{n}-, n=2$; rest $n=4$ ) 
Table 2 Blood clearance parameters for ${ }^{125}$ - and ${ }^{111}$ In-CHX-A" DTPA-labelled hu3S193 antibodies

\begin{tabular}{|c|c|c|c|c|c|c|c|}
\hline Radiolabel & Antibody & $t_{1 / 2 a}(h)$ & $A_{a}^{a}(\% \mid D / g)$ & $t_{1 / 2 \beta}(h)$ & $A_{\beta}(\% \mid D / g)$ & $A \cup C^{b}(\% I D / g h)$ & $\mathrm{MRT}^{\mathrm{C}}(\mathrm{h})$ \\
\hline \multirow[t]{5}{*}{$\overline{125} \mid-$} & Wild type & 2.5 & 36.5 & 140.7 & 35.3 & 7304 & 199.4 \\
\hline & $1253 \mathrm{~A}$ & 0.7 & 18.1 & 13.2 & 60.0 & 1161 & 18.7 \\
\hline & $\mathrm{H} 310 \mathrm{~A}$ & 0.6 & 17.7 & 7.6 & 74.0 & 824 & 10.7 \\
\hline & $\mathrm{H} 435 \mathrm{~A}$ & 1.2 & 28.8 & 15.6 & 56.2 & 1316 & 21.7 \\
\hline & $1253 \mathrm{~A} / \mathrm{H} 310 \mathrm{~A}$ & 0.5 & 15.7 & 7.3 & 66.5 & 710 & 10.3 \\
\hline \multirow[t]{5}{*}{${ }^{111}$ In-CHX-A" DTPA- } & Wild type & 2.6 & 37.2 & 151.5 & 31.5 & 7033 & 214.4 \\
\hline & $1253 \mathrm{~A}$ & 2.7 & 34.1 & 63.2 & 44.6 & 4200 & 88.46 \\
\hline & $\mathrm{H} 310 \mathrm{~A}$ & 1.5 & 38.9 & 24.4 & 46.9 & 1732 & 33.6 \\
\hline & $\mathrm{H} 435 \mathrm{~A}$ & 1.9 & 39.6 & 62.2 & 38.6 & 3567 & 87.0 \\
\hline & I253A/H310A & 0.5 & 20.0 & 9.1 & 58.7 & 781 & 12.9 \\
\hline
\end{tabular}

${ }^{a}$ Amplitudes of the two components $t_{1 / 2 \alpha}$ and $t_{1 / 2 \beta}$ are given by $A_{\alpha}$ and $A_{\beta}$, respectively, where the sum of $A_{\alpha}$ and $A_{\beta}$ is the total \%ID/g

${ }^{\mathrm{b}} \mathrm{AUC}$ area under the curve; time integral of the blood uptake

${ }^{\mathrm{C}} M R T$ mean residence time; used to give a single variable for blood clearance

wild type is shown in Additional file $1\left({ }^{111}\right.$ In-labelled variants versus ${ }^{111}$ In-labelled wild type, Additional file 1: Figure S1; ${ }^{131}$ I-labelled variants versus ${ }^{125}$ I-labelled wild type, Additional file 1: Figure S2). Radioiodinated hu3S193 antibodies cleared faster than their ${ }^{111}$ In-chelated counterparts, and as a result, lower tumour uptake was observed with radioiodinated variants compared to their ${ }^{111}$ In-chelated counterparts (Fig. 1, Additional file 1: Table S2 and Additional file 1: Table S3).

Although a significant reduction in tumour uptake was observed with faster clearing hu3S193 mutants, more favourable tumour-to-blood ratios were observed for ${ }^{111}$ In-labelled hu3S193 H310A and ${ }^{111}$ In-labelled hu3S193 I253A/H310A compared to wild type (Table 3). At $48 \mathrm{~h}$ post injection, ${ }^{111}$ In-labelled wild type showed a tumour-to-blood ratio of $2.70 \pm 0.26$ compared to $5.04 \pm$ 2.04 for H310A $(P<0.05)$ and $32.81 \pm 7.10$ for $\mathrm{I} 253 \mathrm{~A} /$ H310A $(P<0.001)$. Tumour uptake was significantly lower for all ${ }^{131}$ I-labelled mutants compared to wild type $(P<0.0001)$ at all time points except $4 \mathrm{~h}$ post injection (Fig. 1, Table 3, Additional file 1: Table S3, Additional file 1: Figure S2). No significant differences in tumour uptake were observed between mutants. As seen with the ${ }^{111}$ In-labelled mutants at $48 \mathrm{~h}$ post injection, tumour-to-blood ratios for ${ }^{131}$ I-labelled mutants were more favourable than wild type (Table 3 ).

As expected for large proteins $(>60 \mathrm{kDa})$, all hu3S193 variants exhibited a hepatic clearance. This is evidenced by the ${ }^{111}$ In-labelled variants showing an increase in liver uptake at early time points with increased blood clearance rates (Fig. 1f). Liver uptake for the slowest clearing mutants hu3S193 H435A and hu3S193 I253A peaked at $4 \mathrm{~h}$ p.i. $(9.49 \pm 0.76 \% \mathrm{ID} / \mathrm{g}$ and $15.52 \pm 3.45 \% \mathrm{ID} / \mathrm{g}$, respectively). The fastest mutant hu3S193 I253A/H310A reached a maximum liver uptake at $24 \mathrm{~h}$ p.i. $(18.68 \pm 1.34 \% \mathrm{ID} / \mathrm{g})$.

\section{Improved therapeutic ratio with Fc-engineered hu3S193 mutants}

To calculate the therapeutic ratio for hu3S193 variants with faster blood clearance, AUC values were calculated for blood of labelled $\left({ }^{131} \mathrm{I}_{-},{ }^{90} \mathrm{Y}_{-},{ }^{177} \mathrm{Lu}-\right)$ antibodies and tumour-to-blood AUC ratios were calculated (Table 4). With exception of the I253A variant, all mutants demonstrated higher or similar tumour-to-blood AUC ratios compared to hu3S193 wild type. The highest increase in tumour-to-blood AUC ratio was observed with the metallabelled mutants with ${ }^{177} \mathrm{Lu}-\mathrm{CHX}-\mathrm{A}$ " DTPA-hu3S193 I253A/H310A showing a doubling in the tumour-to-blood AUC ratio compared to hu3S193 wild type and other variants. No increase in tumour-to-blood AUC ratios was observed with the faster clearing radioiodinated variants.

AUC ratios were also calculated for tumour-to-liver and tumour-to-kidney as these clearing organs could be dose limiting, especially for radiometal-labelled mutants. The lowest tumour-to-liver AUC ratios were observed with the ${ }^{90}$ Y-labelled (1) and ${ }^{177}$ Lu-labelled (1.9) hu3S193 I253A/H310A. Tumour-to-kidney ratios were lowest for ${ }^{90} \mathrm{Y}$-hu3S193 I253A (2.4) and ${ }^{90} \mathrm{Y}$-hu3S193 I253A/H310A (2.5) followed by ${ }^{90}$ Y-hu3S193 H310A (3.1) and ${ }^{177}$ Lu-hu3S193 H310A (3.1). Tumour-to-liver AUC ratios were superior for the ${ }^{131}$ I-labelled variants with the highest tumour-to-liver AUC ratio observed with ${ }^{131}$ I-hu3S193 I253A/H310A (5.6).

\section{Dosimetry calculation for radioimmunotherapy}

To predict which hu3S193 mutant would be the best candidate for radioimmunotherapy, dose-limiting toxicity for the bone marrow was set at 150 cGy [21]. ${ }^{90}$ Y-CHX-A" DTPA-hu3S193 H310A reached a tumour-absorbed dose 1.2-fold higher than hu3S193 wild type (H310A, 4050 cGy; wild type, 3300 cGy) (Fig. 2). ${ }^{177}$ Lu-CHX-A" DTPA-hu3S193 I253A/H310A 

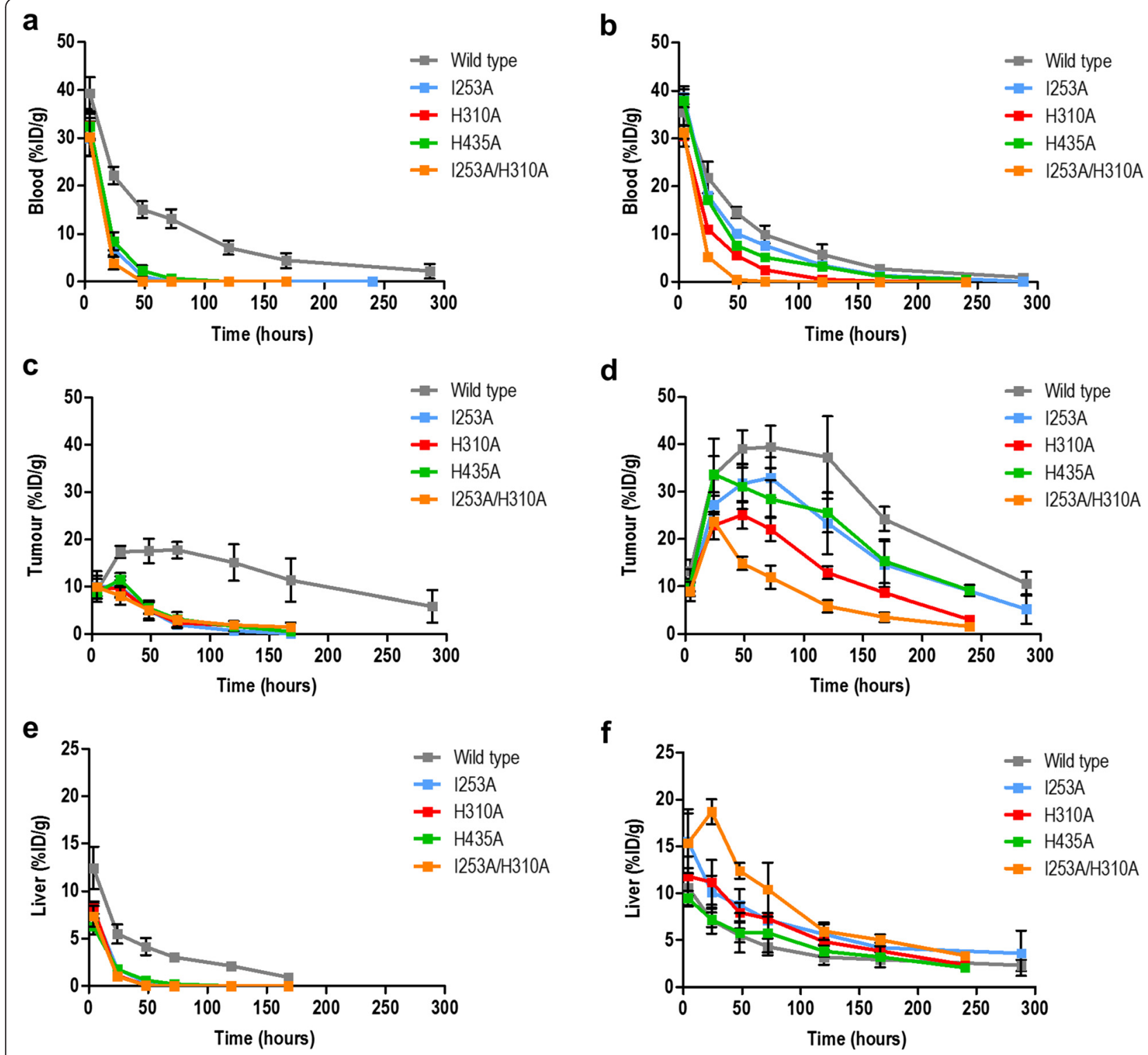

Fig. 1 Biodistribution with ${ }^{\mathbf{1 3 1}} \mid-(\mathbf{a}, \mathbf{c}$ and $\mathbf{e})$ and ${ }^{{ }^{111}} \mathrm{In}-\mathrm{CHX}-\mathrm{A} "$ DTPA-labelled (b, $\mathbf{d}$ and $\mathbf{f}$ ) hu3S193 antibodies. $n=5 ;$ bars, SD

was predicted to be the best candidate for ${ }^{177}$ Lu-therapy, reaching a tumour dose of 8947 cGy compared to 4650 cGy for ${ }^{177} \mathrm{Lu}$-labelled wild type, limited by bone marrow toxicity (Fig. 2).

\section{Nano-SPECT imaging with ${ }^{177}$ Lu-CHX-A" DTPA-labelled hu3S193 wild type and ${ }^{177} \mathrm{Lu}-\mathrm{CHX}-\mathrm{A}$ " DTPA-labelled hu3S193 I253A/H310A}

Qualitative imaging was performed with hu3S193 wild type, hu3S193 I253A/H310A and huA33 control in A431 tumour-bearing mice. Mice were injected with 3.7 $\mathrm{MBq}(100 \mu \mathrm{Ci}, 270 \mu \mathrm{g})$ of radiolabelled antibody. HuA33 wild type was used as a negative control as the
A431 cell line does not express A33 antigen. Quality controls showed that at day 0 , only $3.4 \%$ of ${ }^{177} \mathrm{Lu}-\mathrm{CHX}-\mathrm{A}^{\prime \prime}$ DTPA-labelled huA33 bound to A431 cells in vitro. In contrast, ${ }^{177} \mathrm{Lu}-\mathrm{CHX}-\mathrm{A} "$ DTPA-labelled hu3S193 wild type and $1253 \mathrm{~A} / \mathrm{H} 310 \mathrm{~A}$ demonstrated a good binding at day $0(72.6 \pm 4.3 \%$ and $53.9 \pm 3.9 \%$, respectively; $n=3$, SD) gradually decreasing to $25.0 \pm 2.5 \%$ (wild type) versus 18.4 $\pm 1.4 \%(\mathrm{I} 253 \mathrm{~A} / \mathrm{H} 310 \mathrm{~A})$ after 6 days of incubation in human serum at $37^{\circ} \mathrm{C}$.

Whole body scans were obtained at $48 \mathrm{~h}$ post injection (Fig. 3). By $48 \mathrm{~h}$, images showed tumour uptake for ${ }^{177} \mathrm{Lu}-\mathrm{CHX}-\mathrm{A}$ " DTPA-labelled hu3S193 wild type (Fig. 3a, d) and I253A/H310A (Fig. 3b, e). No tumour 
Table 3 Tumour uptake, blood levels and tumour-to-blood ratios for ${ }^{131} \mathrm{I}$ - and ${ }^{111} \mathrm{In}-\mathrm{CHX}$-A" DTPA-labelled hu3S193 antibody variants in A431 tumour-bearing mice

\begin{tabular}{|c|c|c|c|c|c|c|c|}
\hline Antibody & Time (hours) & Tumour (\%ID/g) & Blood (\%ID/g) & $T / B$ & Tumour (\%ID/g) & Blood (\%ID/g) & $T / B$ \\
\hline & & ${ }^{131} \mid$ & & & ${ }^{111} \operatorname{In}$ & & \\
\hline \multirow[t]{6}{*}{ Wild type } & 4 & $9.02 \pm 0.73^{\mathrm{a}}$ & $39.37 \pm 3.33$ & $1: 4$ & $13.17 \pm 2.40$ & $35.56 \pm 5.48$ & $1: 3$ \\
\hline & 24 & $17.37 \pm 1.25$ & $22.17 \pm 1.81$ & $1: 1$ & $33.42 \pm 7.75$ & $21.83 \pm 3.32$ & $2: 1$ \\
\hline & 48 & $17.58 \pm 2.60$ & $15.09 \pm 1.70$ & $1: 1$ & $39.01 \pm 3.92$ & $14.50 \pm 1.11$ & $3: 1$ \\
\hline & 72 & $17.76 \pm 1.72$ & $13.18 \pm 1.91$ & $1: 1$ & $39.27 \pm 4.33$ & $9.97 \pm 1.85$ & $4: 1$ \\
\hline & 120 & $15.10 \pm 3.89$ & $7.13 \pm 1.46$ & $2: 1$ & $37.26 \pm 8.67$ & $5.78 \pm 2.12$ & $6: 1$ \\
\hline & 168 & $11.40 \pm 4.56$ & $4.44 \pm 1.56$ & $2: 1$ & $24.24 \pm 2.57$ & $1.06 \pm 0.32$ & $9: 1$ \\
\hline \multirow[t]{6}{*}{ I253A } & 4 & $10.01 \pm 3.25$ & $29.95 \pm 3.59$ & $1: 3$ & $9.64 \pm 0.74$ & $38.74 \pm 3.57$ & $1: 4$ \\
\hline & 24 & $9.95 \pm 2.26$ & $6.94 \pm 1.34$ & $1: 1$ & $27.17 \pm 2.00$ & $17.99 \pm 1.57$ & $2: 1$ \\
\hline & 48 & $5.07 \pm 2.10$ & $1.09 \pm 0.32$ & $5: 1$ & $31.75 \pm 3.98$ & $10.19 \pm 1.04$ & $3: 1$ \\
\hline & 72 & $2.03 \pm 0.81$ & $0.04 \pm 0.08$ & $48: 1$ & $33.11 \pm 4.05$ & $7.64 \pm 1.32$ & $4: 1$ \\
\hline & 120 & $0.78 \pm 0.79$ & $0.00 \pm 0.00$ & $>500: 1$ & $23.68 \pm 6.52$ & $2.99 \pm 0.73$ & $8: 1$ \\
\hline & 168 & $0.10 \pm 0.14$ & $0.00 \pm 0.00$ & $>500: 1$ & $14.66 \pm 4.80$ & $1.14 \pm 0.63$ & $13: 1$ \\
\hline \multirow[t]{6}{*}{$\mathrm{H} 435 \mathrm{~A}$} & 4 & $8.79 \pm 0.45$ & $32.46 \pm 2.63$ & $1: 4$ & $10.25 \pm 1.30$ & $37.97 \pm 2.68$ & $1: 4$ \\
\hline & 24 & $11.52 \pm 1.38$ & $8.46 \pm 1.89$ & $1: 1$ & $33.69 \pm 3.77$ & $17.09 \pm 1.59$ & $2: 1$ \\
\hline & 48 & $5.53 \pm 1.18$ & $2.27 \pm 1.21$ & $2: 1$ & $31.10 \pm 4.76$ & $7.65 \pm 1.60$ & $4: 1$ \\
\hline & 72 & $3.18 \pm 0.22$ & $0.69 \pm 0.17$ & $5: 1$ & $28.48 \pm 4.00$ & $5.18 \pm 1.40$ & $6: 1$ \\
\hline & 120 & $1.64 \pm 1.09$ & $0.00 \pm 0.00$ & $>500: 1$ & $25.60 \pm 4.16$ & $3.19 \pm 0.62$ & $8: 1$ \\
\hline & 168 & $0.54 \pm 0.58$ & $0.00 \pm 0.00$ & $>500: 1$ & $15.34 \pm 4.65$ & $1.16 \pm 0.62$ & $13: 1$ \\
\hline \multirow[t]{6}{*}{$\mathrm{H} 310 \mathrm{~A}$} & 4 & $9.80 \pm 1.83$ & $32.56 \pm 3.00$ & $1: 3$ & $10.79 \pm 2.87$ & $30.52 \pm 5.06$ & $1: 3$ \\
\hline & 24 & $9.58 \pm 1.73$ & $3.85 \pm 0.35$ & $3: 1$ & $22.85 \pm 2.93$ & $11.05 \pm 1.62$ & $2: 1$ \\
\hline & 48 & $5.10 \pm 1.87$ & $0.01 \pm 0.02$ & $>500: 1$ & $25.10 \pm 2.91$ & $5.61 \pm 2.01$ & $5: 1$ \\
\hline & 72 & $2.43 \pm 1.10$ & $0.00 \pm 0.00$ & $>500: 1$ & $22.12 \pm 2.55$ & $2.56 \pm 0.60$ & $9: 1$ \\
\hline & 120 & $1.81 \pm 0.71$ & $0.00 \pm 0.00$ & $>500: 1$ & $12.89 \pm 1.33$ & $0.54 \pm 0.16$ & $24: 1$ \\
\hline & 168 & $1.45 \pm 0.99$ & $0.00 \pm 0.00$ & $>500: 1$ & $8.64 \pm 0.96$ & $0.17 \pm 0.06$ & $51: 1$ \\
\hline \multirow[t]{6}{*}{ I253A/H310A } & 4 & $9.90 \pm 2.42$ & $30.20 \pm 3.97$ & $1: 3$ & $8.92 \pm 2.00$ & $28.84 \pm 6.05$ & $1: 3$ \\
\hline & 24 & $8.04 \pm 1.82$ & $3.88 \pm 1.32$ & $2: 1$ & $23.72 \pm 0.85$ & $5.28 \pm 0.81$ & $5: 1$ \\
\hline & 48 & $5.10 \pm 0.76$ & $0.06 \pm 0.09$ & $80: 1$ & $14.84 \pm 1.43$ & $0.46 \pm 0.07$ & $32: 1$ \\
\hline & 72 & $3.04 \pm 1.58$ & $0.00 \pm 0.00$ & $>500: 1$ & $11.92 \pm 2.46$ & $0.08 \pm 0.03$ & $154: 1$ \\
\hline & 120 & $1.92 \pm 0.53$ & $0.00 \pm 0.00$ & $>500: 1$ & $5.85 \pm 1.31$ & $0.00 \pm 0.00$ & $>500: 1$ \\
\hline & 168 & $1.43 \pm 0.27$ & $0.00 \pm 0.00$ & $>500: 1$ & $3.52 \pm 1.00$ & $0.00 \pm 0.00$ & $>500: 1$ \\
\hline
\end{tabular}

${ }^{\mathrm{a}}$ Data presented as percentage injected dose per gramme tissue (mean $\pm \mathrm{SD}, n=5$ )

uptake was shown with the huA33 control demonstrating specific tumour uptake of hu3S193 wild type and I253A/H310A mutant in A431 tumours (Fig. 3c, 3f). High tumour uptake, high blood pool and background activity for hu3S193 wild type compared to hu3S193 I253A/H310A were observed. Volume of interest analysis for the heart, liver and tumour was used to calculate averaged uptake per pixel. Hu3S193 wild type had a lower tumour-to-heart ratio compared to I253A/H310A (wild type, $2.53 \pm 0.07$; I253A/H310 A, $7.34 \pm 2.05 ; n=2)$. The tumour-to-liver ratio was higher for wild type $(4.40 \pm 1.51, n=2)$ compared to I253A/H310A $(1.35 \pm 0.15 ; n=2)$.
In a separate biodistribution study, mice were injected with ${ }^{177} \mathrm{Lu}-\mathrm{CHX}-\mathrm{A}$ " DTPA-labelled hu3S193 wild type or I253A/H310A $(n=5)$. After 48 h post injection, mice were sacrificed and organs were counted for radioactivity (Table 5). Biodistribution results confirmed reduced tumour activity of I253A/H310A $(16.95 \pm 3.60 \% \mathrm{ID} / \mathrm{g})$ compared to hu3S193 wild type $(44.81 \pm 3.35 \% \mathrm{ID} / \mathrm{g} ; P<0.01)$. Tumour uptake of ${ }^{177} \mathrm{Lu}-$ CHX-A" DTPA-labelled I253A/H310A was specific and significantly higher than ${ }^{177} \mathrm{Lu}-\mathrm{CHX}-\mathrm{A}$ " DTPA-labelled huA33 (10.35 $\pm 0.54, P<0.01)$. Importantly, tumour-toblood ratios were $2.93 \pm 0.65$ (hu3S193 wild type), $0.49 \pm$ 0.30 (huA33 control) and $16.56 \pm 3.71$ (hu3S193 I253A/ 
Table 4 AUC values (\%ID/g h) and therapeutic ratios of ${ }^{131} \mathrm{I}-,{ }^{90} \mathrm{Y}-\mathrm{CHX}-\mathrm{A}$ " DTPA- and ${ }^{177} \mathrm{Lu}-\mathrm{CHX}-\mathrm{A}$ " DTPA-labelled hu3S193 antibody variants in A431 tumour-bearing mice

\begin{tabular}{|c|c|c|c|c|c|c|c|c|}
\hline Radiolabel & Antibody & $\mathrm{A} \cup \mathrm{C}_{\text {tumour }}$ & $A \cup C_{\text {blood }}$ & $A \cup C_{\text {liver }}$ & $\mathrm{A} \cup \mathrm{C}_{\text {kidney }}$ & $T / L^{a}$ & $\mathrm{~T} / \mathrm{K}^{\mathrm{b}}$ & $T / B^{C}$ \\
\hline \multirow[t]{5}{*}{$\overline{{ }^{90} Y-C H X-A " ~ D T P A-~}$} & Wild type & 2849 & 1276 & 498 & 636 & 5.7 & 4.5 & 2.2 \\
\hline & $\mathrm{H} 435 \mathrm{~A}$ & 2168 & 964 & 514 & 561 & 4.2 & 3.9 & 2.3 \\
\hline & $1253 \mathrm{~A}$ & 1541 & 1126 & 738 & 633 & 2.1 & 2.4 & 1.4 \\
\hline & $\mathrm{H} 310 \mathrm{~A}$ & 1506 & 559 & 676 & 482 & 2.2 & 3.1 & 2.7 \\
\hline & I253A/H310A & 1037 & 418 & 1037 & 412 & 1.0 & 2.5 & 2.5 \\
\hline \multirow[t]{5}{*}{${ }^{177}$ Lu-CHX-A" DTPA- } & Wild type & 5203 & 1709 & 833 & 1265 & 6.3 & 4.1 & 3.1 \\
\hline & $\mathrm{H} 435 \mathrm{~A}$ & 4076 & 1235 & 835 & 932 & 4.9 & 4.4 & 3.3 \\
\hline & $1253 \mathrm{~A}$ & 3514 & 1362 & 1189 & 1029 & 3.0 & 3.4 & 2.6 \\
\hline & $\mathrm{H} 310 \mathrm{~A}$ & 2400 & 783 & 1104 & 774 & 2.2 & 3.1 & 3.1 \\
\hline & 1253A/H310A & 2699 & 453 & 1421 & 539 & 1.9 & 5.0 & 6.0 \\
\hline \multirow[t]{5}{*}{${ }^{131} \mid-$} & Wild type & 2739 & 2085 & 560 & 659 & 4.9 & 4.2 & 1.3 \\
\hline & $\mathrm{H} 435 \mathrm{~A}$ & 679 & 516 & 129 & 175 & 5.2 & 3.9 & 1.3 \\
\hline & $1253 \mathrm{~A}$ & 568 & 516 & 141 & 159 & 4.0 & 3.6 & 1.1 \\
\hline & $\mathrm{H} 310 \mathrm{~A}$ & 655 & 439 & 118 & 125 & 5.5 & 5.2 & 1.5 \\
\hline & I253A/H310A & 602 & 422 & 107 & 120 & 5.6 & 5.0 & 1.4 \\
\hline
\end{tabular}

${ }_{\mathrm{a}}^{\mathrm{T}} / \mathrm{L}, \mathrm{AUC} \mathrm{C}_{\text {tumour }}$-to-AUC $\mathrm{Cliver}_{\text {ratio }}$

${ }^{\mathrm{b}} \mathrm{T} / \mathrm{K}, \mathrm{AUC} \mathrm{C}_{\text {tumour }}$-to- $\mathrm{AU} \mathrm{C}_{\text {kidney }}$ ratio

${ }^{\mathrm{C}} \mathrm{T} / \mathrm{B}, \mathrm{AUC} \mathrm{C}_{\text {tumour }}$-to-AUC $\mathrm{C}_{\text {blood }}$ ratio

H310A). Tumour-to-liver ratios were $7.71 \pm 1.26$ (hu3S193 wild type), $6.37 \pm 0.62$ (huA33 control) and $1.20 \pm 0.23$ (hu3S193 I253A/H310A).

Higher protein doses were used for imaging with ${ }^{177}$ Lu-CHX-A" DTPA-labelled hu3S193 antibodies $(270 \mu \mathrm{g})$ and biodistribution $(100 \mu \mathrm{g})$. Tumour uptake with $5 \mu \mathrm{g}(\sim 0.25 \mathrm{mg} / \mathrm{kg}){ }^{111}$ In-CHX-A" DTPA-labelled hu3S193 antibodies was not significantly different from

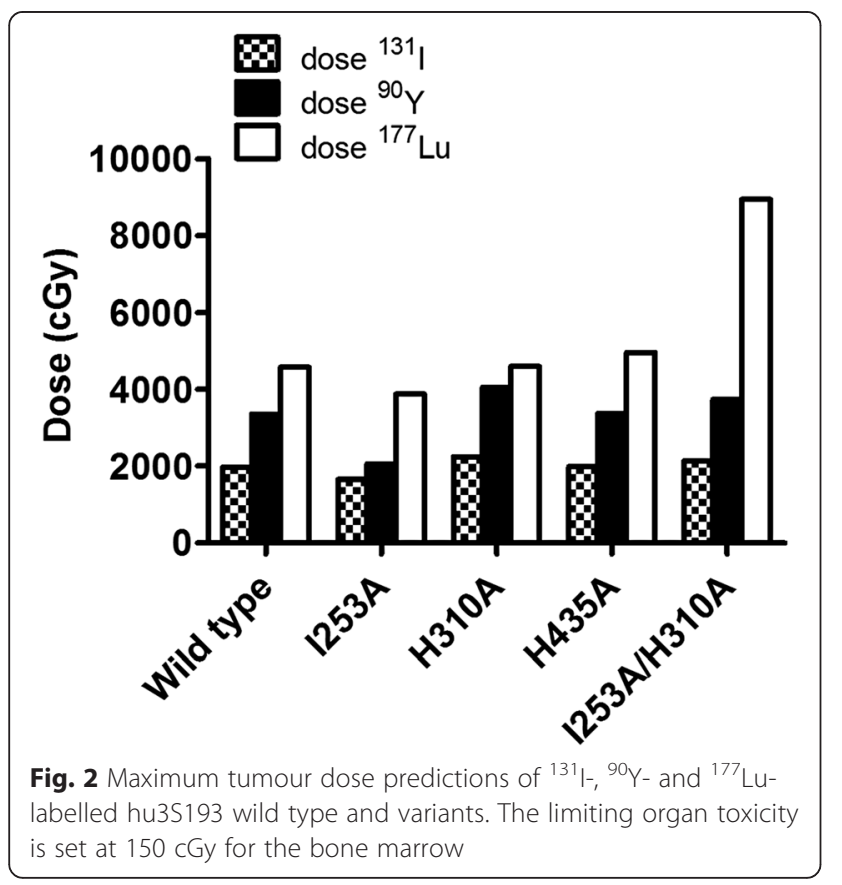

tumour uptake with $100 \mu \mathrm{g}(\sim 5 \mathrm{mg} / \mathrm{kg}){ }^{177} \mathrm{Lu}-\mathrm{CHX}-\mathrm{A} "$ DTPA-labelled hu3S193 antibodies as shown in Additional file 1: Figure S3, suggesting that at least at the $5 \mathrm{mg} / \mathrm{kg}$ dose level, no blocking of receptor has occurred.

\section{Discussion}

Fc engineering is a promising technique to increase the therapeutic ratio for payload delivery. This approach aims to increase the therapeutic efficacy by reducing the terminal half-life of antibodies or Fc-containing antibody constructs, thus reducing the dose-limiting toxicity to the blood and bone marrow of intact radiolabelled therapeutic antibodies. In this study, four variants of an intact IgG1 antibody, hu3S193, with a broad range in half-life were created by site-directed mutagenesis and analysed in blood clearance studies and biodistribution studies. Our results show that hu3S193 can be engineered with improved therapeutic ratios for ${ }^{90} \mathrm{Y}$ - and ${ }^{177} \mathrm{Lu}$-based therapy, with the best candidate being hu3S193 I253A/ H310A for ${ }^{177} \mathrm{Lu}$-based therapy, achieving almost double tumour-to-blood AUC ratios compared to wildtype hu3S193.

Four Fc variants of an intact IgG1 antibody, hu3S193, with a broad range in serum half-life were created by site-directed mutagenesis and analysed in preclinical blood clearance studies and biodistribution studies. Non-specific uptake of hu3S193 wild type in a Lewis-Ynegative cell line SW1222 is known to be low [26]; in addition, in this study, a non-specific IgG1 control 




Fig. 3 Nano-SPECT/MRI imaging with ${ }^{177}$ Lu-CHX-A" DTPA-labelled hu3S193 wild type (a, d) and I253A/H310A mutant (b, e) and huA33 wild type antibody (c, $\mathbf{f})$ at day 2 post injection in A431 tumour-bearing mice. Representative whole body surface-rendered MRI images (a-c) and maximum intensity projection SPECT image $(\mathbf{d}-\mathbf{f})$ are shown for each antibody. The T1 weighted MRI images clearly show the tumour (grey solid mass) surface of the lower abdomen, corresponding to the specific uptake of ${ }^{177}$ Lu-CHX-A" DTPA-labelled hu3S193 wild type and I253A/H310A in tumours expressing Ley. Specific uptake of both hu3S193 wild type and hu3S193 I253A/H310A was demonstrated by the absence of huA33 uptake in the A33 antigen-negative A431 tumours

antibody huA33 showed low uptake in A431 tumours at $72 \mathrm{~h}$ post injection. Therefore, the tumour uptake of radiolabelled hu3S193 mutants was specific and antigen-mediated.

Early engineering approaches using deletion of constant domains to reduce the serum half-life of antibodies have shown that tumour-to-normal dose ratios can be improved [1, 10, 11, 37]. More recently, studies by Kenanova et al. reported on therapy prospects of radioiodinated and radiometal-labelled $\mathrm{Fc}$-engineered anti-carcinoembryonic antigen (CEA) scFv-Fc fragments $[20,21]$. Dosimetry calculations predicted that the ${ }^{131}$ I-labelled scFv-Fc H310A/H435Q could deliver $>7000 \mathrm{cGy}$, limited by red marrow toxicity. ${ }^{90}$ Y-labelled 
Table 5 Biodistribution at 48 h post injection of ${ }^{177} \mathrm{Lu}-\mathrm{CHX}-\mathrm{A} "$ DTPA-labelled hu3S193 wild type and I253A/H310A in tumourbearing mice

\begin{tabular}{lccr}
\hline Tissue & Hu3S193 wild type & Hu3S193 I253A/H310A & \multicolumn{1}{l}{ HuA33 } \\
\hline Tumour & $44.81 \pm 3.35$ & $16.95 \pm 3.60$ & $10.35 \pm 0.54$ \\
Blood & $15.67 \pm 2.47$ & $1.05 \pm 0.27$ & $20.88 \pm 1.25$ \\
Liver & $5.99 \pm 1.43$ & $14.16 \pm 1.28$ & $6.37 \pm 0.62$ \\
Spleen & $9.32 \pm 1.33$ & $13.77 \pm 2.57$ & $9.60 \pm 0.88$ \\
Kidney & $8.27 \pm 4.36$ & $3.91 \pm 0.41$ & $7.98 \pm 0.51$ \\
Lung & $9.79 \pm 1.55$ & $1.95 \pm 0.25$ & $12.06 \pm 0.99$ \\
Heart & $5.72 \pm 1.09$ & $2.66 \pm 0.16$ & $6.03 \pm 0.49$ \\
Muscle & $2.01 \pm 0.44$ & $1.03 \pm 0.08$ & $2.34 \pm 0.44$ \\
\hline
\end{tabular}

scFv-Fc I253A was best suited for ${ }^{90} \mathrm{Y}$ delivery, although dose predictions did not match the intact cT84.66 antibody. The current study extends their findings to an intact IgG1 and includes predictions for ${ }^{177} \mathrm{Lu}$-based therapy. In contrast to the anti-CEA study by Kenanova et al., the radioiodinated anti-Le ${ }^{\mathrm{y}}$ hu3S193 variants cleared much faster than the radioiodinated scFv-Fc fragments, and therefore, no therapeutic benefit could be obtained from the radioiodinated hu3S193 variants. The hu3S193 variants might be more sensitive to deiodination in vivo compared to the $\mathrm{scFv}-\mathrm{Fc}$ variants. To study the benefit for RIT of using radioiodinated hu3S193 variants with faster blood clearance, other radioiodination methods such as site-specific radioiodination of cysteine-containing hu3S193 variants could be explored [38].

Whilst a doubling in dose to the maximum predicted dose calculated for hu3S193 wild type was predicted and a doubling in the tumour-to-blood AUC ratios achieved, the dose needed for tumour eradication in patients is likely to be higher than that achievable with a single infusion. Le $\mathrm{L}^{\mathrm{y}}$-expressing tumours such as colon, lung, ovarian and breast cancer require radiation doses of at least $60 \mathrm{~Gy}$ to eradicate solid tumours in patients [1]. Reducing the half-life of systemically administered antibodies is usually associated with reduced uptake in tumour; however, AUC ratios of tumour and blood address the varying effects of alterations in antibody kinetics, and our results confirm that selective IgG1 mutations do provide benefit in therapeutic ratios. Approaches to further increase therapeutic efficacy of Fcengineered intact antibodies with reduced half-lives can include dose fractionation [39], use in pretargeting radioimmunotherapy approaches [40] or combination with chemotherapy $[28,29]$. To date, pretargeting approaches show advantages compared to improvements in one-step RIT for improved tumour-to-normal tissue AUC ratios and tumour responses in preclinical models of solid tumours [1], but challenges remain to develop non-immunogenic and translatable approaches for human trials.

Due to the toxicity limitations of RIT and patient tumour variability, it is useful to develop theranostics to guide dosimetry in patients, exemplified in this study by ${ }^{177} \mathrm{Lu}$-labelled I253A/H310A. The imaging results reflect the biodistribution data; the highest tumour uptake was seen with hu3S193 wild type, but specific tumour uptake was still achievable with the fastest clearing hu3S193 variant I253A/H310A, and tumour-toblood ratios were far higher at earlier time points with the mutant hu3S193 constructs. However, because ${ }^{177} \mathrm{Lu}$ can only be imaged using SPECT cameras, a PET equivalent such as ${ }^{89} \mathrm{Zr}$-labelled I253A/H310A might be a better alternative and may allow better quantification of tumour uptake and saturability in vivo. We are currently evaluating ${ }^{89} \mathrm{Zr}$-labelled hu3S193 variants in tumour-bearing mice in small animal PET studies.

A higher protein dose was used for ${ }^{177}$ Lu-imaging $(270 \mu \mathrm{g})$ and biodistribution $(100 \mu \mathrm{g})$ studies versus ${ }^{111}$ In-biodistribution $(5 \mu \mathrm{g})$ studies. We demonstrated that tumour uptake at 5 and $100 \mu \mathrm{g}$ protein doses were comparable. Lewis-Y expression is very high on A431 cells and similar to MCF-7 cells, estimated to express around $10^{6}-10^{7}$ antibody binding sites [26]. A recent report on ABT-806, a humanised antibody that specifically targets epidermal growth factor receptor (EGFR), reports on cold competition blocking of the 806 antibody in A431 tumours [41]. EGFR is highly expressed in A431 cells, and therefore, more than $20 \mathrm{mg} / \mathrm{kg}$ of cold ABT-806 antibody was needed to allow competition in vivo. It is therefore expected that competition with hu3S193 antibodies will only occur at doses higher than $20 \mathrm{mg} / \mathrm{kg}$, which aligns with the observation that at the $5 \mathrm{mg} / \mathrm{kg}$ dose $(100 \mu \mathrm{g})$, no reduction in tumour uptake was observed at $48 \mathrm{~h}$ post injection.

Although significant increases in therapeutic doses were predicted with some variants compared to hu3S193 wild type, increased toxicities to normal tissue such as the liver and kidneys were also predicted. A shift in toxicity from the bone marrow to liver as toxicity limiting organ for radiometal-labelled antibody variants with a faster blood clearance is not surprising. As the antibody variants clear faster from the body, radioactivity exposure to the blood is reduced. In addition, due to the reduced binding affinity of the variants for FcRn, an increase in catabolism is expected as the variants are no longer recycled in the blood circulation and degraded in the lysosomes (e.g. hu3S193 I253A/H310A) [19]. In contrast to radioiodine, the small radiometal-labelled metabolites are trapped in the lysosomes of hepatocytes [42], and thus, a higher initial uptake of radioactivity observed in the liver is the result of enhanced accumulation of radiometal chelates after degradation of the 
variants in the lysosomes of hepatocytes. However, a mouse model might not be readily translatable to human studies to estimate liver and kidney toxicities developing from catabolites due to differences in stability of radiolabelled conjugates in human serum and relative size of tissue compartments between mouse and human. A theranostic might therefore also aid in appropriate dose selection when using engineered intact antibodies with altered pharmacokinetics.

\section{Conclusions}

Four Fc variants of an intact IgG1 antibody, hu3S193, with a broad range in serum half-life were created by site-directed mutagenesis and analysed in preclinical blood clearance studies and biodistribution studies. We have shown that hu3S193 can be engineered with improved therapeutic ratios for ${ }^{90} \mathrm{Y}$ - and ${ }^{177} \mathrm{Lu}$-based therapy, with the best candidate being hu3S193 I253A/ H310A for ${ }^{177} \mathrm{Lu}$-based therapy. These results are highly relevant to utilising Fc engineering as a tool to improve the clinical application of hu3S193 and other intact antibodies especially for payload delivery.

\section{Additional file}

Additional file 1: Figures S1-S3; Tables S1-S3. (DOC 1691 kb)

\section{Competing interests}

The authors declare that they have no competing interests.

\section{Authors' contributions}

IJGB, LCA and DM engineered, produced and performed QC of the antibodies. IJGB, DM, DC and AR participated in all animal studies. IJGB, SG and GJO participated in data analysis of imaging studies and dosimetry. FTL and MWB were involved in radiolabelling chemistry and QC of radiolabelled antibodies. IJGB, ZL, PAR, AMS were involved in conception and experimental design, drafted the manuscript and critically revised the manuscript. All authors read and approved the final manuscript.

\section{Compliance with ethical standards}

\section{Funding}

This research was supported by National Health and Medical Research Council Project Grants 542512, 1030469, National Health and Medical Research Council Program grant 487922, National Health and Medical Research Council Practitioner Fellowship (A.M.S.), and in part by Ludwig Cancer Research, by funds from the Operational Infrastructure Support Program provided by the Victorian Government, and the Intramural Research Program of the NIH, National Cancer Institute, Centre for Cancer Research.

\section{Research involving Human Participants and/or Animals}

Statement of human rights

This article does not contain any studies with human participants by any of the authors.

Statement on the welfare of animals

All applicable international, national, and/or institutional guidelines for the care and use of animals were followed.

\section{Informed consent}

Not applicable

\section{Author details}

${ }^{1}$ Tumour Targeting Laboratory, Ludwig Institute for Cancer Research and Olivia Newton-John Cancer Research Institute, Melbourne, VIC, Australia. ${ }^{2}$ School of Cancer Medicine, La Trobe University, Melbourne, VIC, Australia. ${ }^{3}$ Department of Molecular Imaging and Therapy, Austin Health, Melbourne, Australia. ${ }^{4}$ Radioimmune and Inorganic Chemistry Section, Radiation Oncology Branch, Center for Cancer Research, National Cancer Institute, Bethesda, MD, USA. ${ }^{5}$ School of Science, RMIT University, Bundoora, VIC, Australia. ${ }^{6}$ Centre for Biomedical Research, Burnet Institute, Melbourne, VIC, Australia. ${ }^{7}$ Department of Immunology, Monash University, Melbourne, VIC, Australia. ${ }^{8}$ Department of Surgery Austin Health, University of Melbourne, Heidelberg, VIC, Australia. ${ }^{9}$ Faculty of Medicine, University of Melbourne, Melbourne, VIC, Australia. ${ }^{10}$ Olivia Newton-John Cancer Research Institute, 145-163 Studley Road, Heidelberg, VIC 3084, Australia.

Received: 26 January 2016 Accepted: 3 March 2016

Published online: 17 March 2016

\section{References}

1. Larson SM, Carrasquillo JA, Cheung NK, Press OW. Radioimmunotherapy of human tumours. Nat Rev Cancer. 2015;15:347-60. doi:10.1038/nrc3925.

2. Brambell FW. The transmission of immunity from mother to young and the catabolism of immunoglobulins. Lancet. 1966;2:1087-93.

3. Roopenian DC, Christianson GJ, Sproule TJ, Brown AC, Akilesh S, Jung N, et al. The MHC class I-like lgG receptor controls perinatal lgG transport, IgG homeostasis, and fate of lgG-Fc-coupled drugs. J Immunol. 2003;170:3528-33.

4. Junghans RP, Anderson CL. The protection receptor for lgG catabolism is the beta2-microglobulin-containing neonatal intestinal transport receptor. Proc Natl Acad Sci U S A. 1996;93:5512-6.

5. Ghetie V, Hubbard JG, Kim JK, Tsen MF, Lee Y, Ward ES. Abnormally short serum half-lives of IgG in beta 2-microglobulin-deficient mice. Eur J Immunol. 1996;26:690-6. doi:10.1002/eji.1830260327.

6. Simister NE, Mostov KE. An Fc receptor structurally related to MHC class I antigens. Nature. 1989;337:184-7. doi:10.1038/337184a0.

7. Stein R, Govindan SV, Chen S, Reed L, Richel H, Griffiths $G L$, et al. Radioimmunotherapy of a human lung cancer xenograft with monoclonal antibody RS7: evaluation of (177)Lu and comparison of its efficacy with that of (90)Y and residualizing (131)I. J Nucl Med. 2001;42:967-74.

8. Press OW, Shan D, Howell-Clark J, Eary J, Appelbaum FR, Matthews D, et al. Comparative metabolism and retention of iodine-125, yttrium-90, and indium111 radioimmunoconjugates by cancer cells. Cancer Res. 1996;56:2123-9.

9. Naruki Y, Carrasquillo JA, Reynolds JC, Maloney PJ, Frincke JM, Neumann RD, et al. Differential cellular catabolism of $111 \mathrm{ln}$, 90Y and $125 \mathrm{I}$ radiolabeled T101 antiCD5 monoclonal antibody. Int J Rad Appl Instrum B. 1990;17:201-7.

10. Holliger $P$, Hudson PJ. Engineered antibody fragments and the rise of single domains. Nat Biotechnol. 2005:23:1126-36. doi:10.1038/nbt1142.

11. Burvenich IJG, Scott AM. The delivery construct: maximizing the therapeutic ratio of targeted radionuclide therapy. In: Speer TW, editor. Targeted radionuclide therapy. Philadelphia: Lippincott Williams \& Wilkins; 2011. p. 236-48.

12. Clarke K, Lee FT, Brechbiel MW, Smyth FE, Old LJ, Scott AM. In vivo biodistribution of a humanized anti-Lewis $Y$ monoclonal antibody (hu3S193) in MCF-7 xenografted BALB/C nude mice. Cancer Res. 2000;60:4804-11.

13. Tahtis K, Lee FT, Smyth FE, Power BE, Renner C, Brechbiel MW, et al. Biodistribution properties of (111)indium-labeled C-functionalized transcyclohexyl diethylenetriaminepentaacetic acid humanized 35193 diabody and $F\left(a b^{\prime}\right)(2)$ constructs in a breast carcinoma xenograft model. Clin Cancer Res. 2001;7:1061-72.

14. Kelly MP, Lee FT, Tahtis K, Power BE, Smyth FE, Brechbiel MW, et al. Tumor targeting by a multivalent single-chain $\mathrm{Fv}$ (scFv) anti-Lewis $\mathrm{Y}$ antibody construct. Cancer Biother Radiopharm. 2008:23:411-23. doi:10.1089/cbr.2007.0450.

15. Goodwin DA, Meares CF, Osen M. Biological properties of biotin-chelate conjugates for pretargeted diagnosis and therapy with the avidin/biotin system. J Nucl Med. 1998;39:1813-8.

16. Kim JK, Firan M, Radu CG, Kim CH, Ghetie V, Ward ES. Mapping the site on human IgG for binding of the MHC class I-related receptor. FcRn Eur J Immunol. 1999;29:2819-25. doi:10.1002/(SICI)1521-4141(199909)29:09<2819:: AID-IMMU2819>3.0.CO;2-6.

17. Martin WL, West Jr AP, Gan L, Bjorkman PJ. Crystal structure at 2.8 A of an FcRn/heterodimeric Fc complex: mechanism of pH-dependent binding. Mol Cell. 2001;7:867-77. doi:10.1016/S1097-2765(01)00230-1. 
18. Shields RL, Namenuk AK, Hong K, Meng YG, Rae J, Briggs J, et al. High resolution mapping of the binding site on human lgG1 for Fc gamma Rl, Fc gamma RII, FC gamma RIII, and FCRn and design of IgG1 variants with improved binding to the Fc gamma R. J Biol Chem. 2001;276:6591-604. doi:10.1074/jbc.M009483200.

19. Roopenian DC, Akilesh S. FCRn: the neonatal Fc receptor comes of age. Nat Rev Immunol. 2007;7:715-25. doi:10.1038/nri2155.

20. Kenanova V, Olafsen T, Crow DM, Sundaresan G, Subbarayan M, Carter NH, et al. Tailoring the pharmacokinetics and positron emission tomography imaging properties of anti-carcinoembryonic antigen single-chain Fv-Fc antibody fragments. Cancer Res. 2005;65:622-31.

21. Kenanova V, Olafsen T, Williams LE, Ruel NH, Longmate J, Yazaki PJ, et al. Radioiodinated versus radiometal-labeled anti-carcinoembryonic antigen single-chain Fv-Fc antibody fragments: optimal pharmacokinetics for therapy. Cancer Res. 2007;67:718-26. doi:10.1158/0008-5472.CAN-06-0454.

22. Olafsen T, Betting D, Kenanova VE, Salazar FB, Clarke P, Said J, et al. Recombinant anti-CD20 antibody fragments for small-animal PET imaging of B-cell lymphomas. J Nucl Med. 2009;50:1500-8. doi:10.2967/jnumed.108.060426.

23. Girgis MD, Olafsen T, Kenanova V, McCabe KE, Wu AM, Tomlinson JS. Targeting CEA in pancreas cancer xenografts with a mutated scFv-FC antibody fragment. EJNMMI Res. 2011;1:24. doi:10.1186/2191-219X-1-24.

24. Hornick JL, Sharifi J, Khawli LA, Hu P, Bai WG, Alauddin MM, et al. Single amino acid substitution in the Fc region of chimeric TNT-3 antibody accelerates clearance and improves immunoscintigraphy of solid tumors. J Nucl Med. 2000;41:355-62.

25. Burvenich IJG, Farrugia W, Lee FT, Catimel B, Liu Z, Makris D, et al. Crossspecies analysis of Fc engineered anti-Lewis-Y human $\operatorname{lgG} 1$ variants in human neonatal receptor transgenic mice reveal importance of S254 and Y436 in binding human neonatal Fc receptor. MAbs, in press

26. Clarke K, Lee FT, Brechbiel MW, Smyth FE, Old LJ, Scott AM. Therapeutic efficacy of anti-Lewis(y) humanized $3 S 193$ radioimmunotherapy in a breast cancer model: enhanced activity when combined with taxol chemotherapy. Clin Cancer Res. 2000;6:3621-8.

27. Lee FT, Mountain AJ, Kelly MP, Hall C, Rigopoulos A, Johns TG, et al. Enhanced efficacy of radioimmunotherapy with 90Y-CHX-A"-DTPA-hu3S193 by inhibition of epidermal growth factor receptor (EGFR) signaling with EGFR tyrosine kinase inhibitor AG1478. Clin Cancer Res. 2005;11:7080s-6s. doi:10.1158/1078-0432.CCR-1004-0019.

28. Kelly MP, Lee FT, Smyth FE, Brechbiel MW, Scott AM. Enhanced efficacy of 90Y-radiolabeled anti-Lewis Y humanized monoclonal antibody hu3S193 and paclitaxel combined-modality radioimmunotherapy in a breast cancer model. J Nucl Med. 2006:47:716-25.

29. Kelly MP, Lee ST, Lee FT, Smyth FE, Davis ID, Brechbiel MW, et al. Therapeutic efficacy of 177Lu-CHX-A"-DTPA-hu3S193 radioimmunotherapy in prostate cancer is enhanced by EGFR inhibition or docetaxel chemotherapy. Prostate. 2009;69:92-104. doi:10.1002/pros.20856.

30. Scott AM, Tebbutt N, Lee FT, Cavicchiolo T, Liu Z, Gill S, et al. A phase I biodistribution and pharmacokinetic trial of humanized monoclonal antibody Hu3s193 in patients with advanced epithelial cancers that express the Lewis-Y antigen. Clin Cancer Res. 2007;13:3286-92.

31. Scott AM, Geleick D, Rubira M, Clarke K, Nice EC, Smyth FE, et al. Construction, production, and characterization of humanized anti-Lewis $Y$ monoclonal antibody 35193 for targeted immunotherapy of solid tumors. Cancer Res. 2000;60:3254-61.

32. Scott AM, Lee FT, Jones R, Hopkins W, MacGregor D, Cebon JS, et al. A phase I trial of humanized monoclonal antibody A33 in patients with colorectal carcinoma: biodistribution, pharmacokinetics, and quantitative tumor uptake. Clin Cancer Res. 2005;11:4810-7. doi:10.1158/1078-0432. CCR-04-2329.

33. Lee FT, O'Keefe GJ, Gan HK, Mountain AJ, Jones GR, Saunder TH, et al. Immuno-PET quantitation of de2-7 epidermal growth factor receptor expression in glioma using 124I-IMP-R4-labeled antibody ch806. J Nucl Med. 2010;51:967-72. doi:10.2967/jnumed.109.068395.

34. Nikula TK, Curcio MJ, Brechbiel MW, Gansow OA, Finn RD, Scheinberg DA. A rapid, single vessel method for preparation of clinical grade ligand conjugated monoclonal antibodies. Nucl Med Biol. 1995;22:387-90.

35. Wu C, Kobayashi H, Sun B, Yoo TM, Paik CH, Gansow OA, et al. Stereochemical influence on the stability of radio-metal complexes in vivo. Synthesis and evaluation of the four stereoisomers of 2-(p-nitrobenzyl)trans-CyDTPA. Bioorg Med Chem. 1997;5:1925-34.
36. Lee FT, Rigopoulos A, Hall C, Clarke K, Cody SH, Smyth FE, et al. Specific localization, gamma camera imaging, and intracellular trafficking of radiolabelled chimeric anti-G(D3) ganglioside monoclonal antibody KM871 in SK-MEL-28 melanoma xenografts. Cancer Res. 2001;61:4474-82.

37. Shen S, Forero A, Meredith RF, LoBuglio AF. Biodistribution and dosimetry of In-111/Y-90-HuCC49 $\Delta$ Ch2 (IDEC-159) in patients with metastatic colorectal adenocarcinoma. Cancer Biother Radiopharm. 2011;26:127-33. doi:10.1089/cbr.2010.0864.

38. Strand J, Nordeman P, Honarvar H, Altai M, Orlova A, Larhed M, et al. Sitespecific radioiodination of HER2-targeting affibody molecules using 4iodophenethylmaleimide decreases renal uptake of radioactivity. ChemistryOpen. 2015;4:174-82. doi:10.1002/open.201402097.

39. Ocean AJ, Pennington KL, Guarino MJ, Sheikh A, Bekaii-Saab T, Serafini AN, et al. Fractionated radioimmunotherapy with (90) Y-clivatuzumab tetraxetan and low-dose gemcitabine is active in advanced pancreatic cancer: a phase 1 trial. Cancer. 2012;118:5497-506. doi:10.1002/cncr.27592.

40. Cheal SM, Xu H, Guo HF, Zanzonico PB, Larson SM, Cheung NK. Preclinical evaluation of multistep targeting of diasialoganglioside GD2 using an lgG-sCFv bispecific antibody with high affinity for GD2 and DOTA metal complex. Mol Cancer Ther. 2014;13:1803-12. doi:10.1158/1535-7163.MCT-13-0933.

41. Reilly EB, Phillips AC, Buchanan FG, Kingsbury G, Zhang Y, Meulbroek JA, et al. Characterization of ABT-806, a humanized tumor-specific anti-EGFR monoclonal antibody. Mol Cancer Ther. 2015;14:1141-51. doi:10.1158/15357163.MCT-14-0820.

42. Duncan JR, Behr TM, DeNardo SJ. Intracellular fate of radiometals. J Nucl Med. 1997;38:829.

\section{Submit your manuscript to a SpringerOpen ${ }^{\circ}$ journal and benefit from:}

- Convenient online submission

- Rigorous peer review

- Immediate publication on acceptance

- Open access: articles freely available online

- High visibility within the field

- Retaining the copyright to your article

Submit your next manuscript at $>$ springeropen.com 